nervæ (nervi exteriores breves parum conspicui) flosculi breviores: glumella inferior lanceolata, convoluta, parte inferiore scariosa, infima ad medium laviter sulcata, punctato-scabra, acuminata, apice 2-4-setosa, setæ inæquales nervos terminantes, aristata, arista 18-20 mm. longa, geniculata, contorta, fere ad medium ciliata, superne scabra; glumella superior hyalina, 2-carinata, ad carinam ciliolata, inferiore brevior; glumellæ hyalinæ, $6 \mathrm{~mm}$. longæ, longe acuminatæ. Ovarium pilosum, stigma plumosum.

In ericetis prope Villa nova de Milfontes trans Tagum cum Avenis sulcata, albinerva, Drosophyllo lusitanico, Simethi bicolore, etc., legit F. Welwitsch.

Affinis Avenis sulcatæ, albinervæ et præcipue Av. flifolix, a quibus sat distincta forma et structura foliorum.

Folia Av. sulcatæ et albinervæ plana, brevia, fasciculis sclerenchymaticis ad marginem et nervum medium tantum dispositis. Folia Av. filifolix $\mathbf{3}-\mathbf{i}$ elevato-costata, fasciculis sclerenchymaticis inforioribus in strata continua confluentibus, inferioribus discretis, omnibus cum nervis connexis, cellulis bulliformibus inter costas. Folia Av. Hackelii lævissime striata ad nervum medium sulcata ibique tantum cellulis bulliformibus dotata, fasciculis sclerenchymaticis inferioribus in strata continua confluentibus cum nervis connexis, fasciculis sclerenchymaticis superioribus rudimentariis nervis cellulis incoloribus connexis.

M. Lutz donne lecture de la communication qui suit :

\title{
Notes lichénologiques,
}

\author{
PAR LE Dr M. BOULY DE LESDAIN.
}

\section{II ${ }^{1}$}

*Buellia ericina; Lecidea ericina Nyl. Circa Lich. Corsic. adnotat. in Flora, 1878, n 29, p. 492.

Averron : St.-Beauzély à Verdalle, $650 \mathrm{~m}$., sur un Châtaignier. Leg. Abbé Soulié, 1905.

Thalle formé de quelques granulations grisâtres, que la potasse rend légèrement jaunàtres. Apothécies très petites, noires marginées, planes devenant un peu convexes à la fin. Epithécium fuligineux, thécium incolore, hypothécium brun. Spores oblongues, uniseptées, brunies, très rarement un peu courbes, longues de $7-10$ sur $3,5-4 \mu$.

Biatorella moriformis Th. Fr. Lich. Scand. II, p. 401 ; Arthonia moriformis Ach., Syn., p. 5.

1. Voy. ce tome p. 241. Le signe (*) indique des espèces ou var. nouvelles pour la France. 
Aveyron : Nant, sur un vieux Châtaignier. Leg. F. Marc, 1903.

Thalle nul. Apothécies convexes, immarginées, noires, devenant pourpres quand on les humecte. Epithécium vert ou olivâtre, thécium et hypothécium incolores. Paraphyses très cohérentes, tortueuses, non renflées au sommet. Thèques claviformes, ventrues, épaissies au sommet. Spores globuleuses, nombreuses, mesurant de 3 à $3,5 \mu$ de diamètre.

Par son épithécium vert, et la réaction de l'Iode sur la gélatine hyméniale, il se rattache bien au B. moriformis, mais la cohérence de ses paraphyses le rapproche aussi du $B$. deplanata. Les trois Biatorella deplanata Almqv., pinicola (Mass) Th. Fr. et moriformis, paraissent bien voisins, peut-être ne faut-il voir dans ces trois espèces que de simples modifications d'un même type. Malheureusement, le peu d'échantillons que je possède ne me permet pas d'élucider cette question qu'il faudrait étudier sur place.

* Arthonia armoricana var. Saltelii B. de Lesd. nova var.

Haute-Garonne : côteaux du Pech David, près Toulouse; sur les jeunes rameaux d'Ormes et de Lilacs. Leg. Saltel, 1903.

Thalle formant une très légère tache grisàtre. Apothécies arrondies, spores oblongues 4-septées, longues de 18-21 sur 6-8 $\mu$. Gélatine hyméniale $\mathbf{I}+$ bleu, puis rouge vineux.

Arthonia tenellula Nyl. in Hue Addenda, p. 259.

Charente : St-Médard. Leg. F. Marc - et Sarthe : Courgains, sur Frène. Leg. Monguillon.

Thalle très mince, formant de petites taches verdâtres. Apothécies noires, très petites, nombreuses. Spores uniseptées, oblongues ou ovoïdes, et alors le plus souvent rétrécies à la cloison, longues de 13-15 sur 6-7 $\mu$.

* Opegrapha nothella Nyl. in Hue Addenda, p. 247.

Averron : St-Beauzély, à la Baume, $700 \mathrm{~m}$., sur un Chêne. Leg. Abbé Soulié, 1905.

Thalle verdi par une algue. Apothécies petites, arrondies ou oblongues, immarginées. légèrement convexes. Epithécium bruni, thécium et hypothécium incolores. Spores oblongues à 3 cloisons, très rarement 4 , longues de 19-2 7 sur 4-:̈ $\mu$, légèrement brunies à la fin. Gélatine hyméniale I + bleu et ensuite vineux.

*Arthopyrenia micropila var. pertusariæ B. de Lesd. nova var.

Hérault : La Salvetat, parasite sur un thalle de Pertusaria; Peupliers sur les bords de l'Agout. Leg. F. Marc, 190 .

Thalle noir de poix, plus épais que dans le type, formant sur le Pertusaria communis des taches irrégulièrement arrondies. Apothécies très petites, nombreuses, situées surtout au centre. Spores ellipsoïdes, uniseptées, longues de 18-19 sur $6 \mu$.

Thelidium Sprucei; Verrucaria Sprucei Ch. Bab., The Brit. spec. of Angiocarp. Lich., p. 54 et 76. 
Averron : Sauclières près Nant, sur des schistes, au bord d'un ruisseau. Leg. F. Marc, 1904.

Thalle gris brunàtre, mince, continu, parfois légèrement fendillé dans les rares places où le thalle est un peu plus épais. Apothécies nombreuses petites, noires, hémisphériques, ombiliquées, recouvertes à la base par le thalle dans lequel elles sont légèrement enfoncées. Spores 8-nées, incolores, 3-septées, à cloisons assez souvent un peu obliques, parfois rétrécies aux cloisons, longues de 30-39 rarement 21 sur 13-15 $\mu$. Paraphyses gélatineuses, flexueuses, peu distinctes.

Sagedia illinita Körb. Syn. Lich. Germ., p. 366; Verrucaria illinita Nyl. in Ny. Bot. Not., p. 158. - Zw., L. E. n ${ }^{\circ} 36,36$ bis et 43 et Zahlb., Krypt. exsicc. edit. a Museo Palat. Vindob., n ${ }^{0} 180$.

Averrox : Bois de Laguiole, $1200 \mathrm{~m}$., sur des Mousses recouvrant un tronc de Hètre. Leg. Abbé Soulié, 1895.

Thalle grisâtre, étendu comme un vernis à la surface des mousses. Apothécies noires, très petites, nombreuses, d'abord planes, arrondies ou ovalaires et recouvertes à la base par le thalle, puis un peu convexes et légèrement ombiliquées. Paraphyses nombreuses, libres, épaisses de 2,5-3 $\mu$. Thèques cylindriques longues de 90-100 $\mu$. Spores 8-nées, sur 2 rangs, fusiformes, droites ou parfois un peu courbes, 6 ou 7 cloisons, longues de 33-39 sur 6-7 $\mu$. Gélatine hyméniale I -

Cette espèce, qui se rencontre principalement sur les troncs des Hêtres, est plus rarement indiquée sur les Mousses. Nylander, dans son Prodromus, signale également ce Lichen "Hypna obducens in sylvis montium editiorum ad Barèges ".

Si l'on voulait appliquer rigoureusement la loi de priorité ce lichen devrait porter le nom de Sagedia faginea.

Polyblastia Nagelii Arn. Die Lich. des Frank. Jura, p. 264; Pyrenula Nægelii Hepp. Abbild. und Beschreib. der Sporen der Flecht Europ., n 469.

Espagne : Catalogne, Hostalets, près Figueras, sur des jeunes branches d'Olivier. Leg. Frère Héribaud, 1905.

Thalle formant une tache blanche assez nettement limitée. Apothécies, noires, légèrement convexes, ou le plus souvent déprimées, recouvertes à la base par le thalle. Spores 4-nées, incolores, oblongues ou ellipsoïdes, murales, longues de $30-33$ sur 13-15 $\mu$. Paraphyses nombreuses, bien développées, anastomosées.

Espèce nouvelle pour l'Espagne.

* Thelopsis subporinella Nyl. var. grisella B. de Lesd. nova. var.; Thelopsis rubella Nyl. var. uniseptata Oliv. in Académie de Géographie Botanique, 190ั, p. 205.

Hérault : Agde, sur des Peupliers. Leg. de Crozals, 1905.

Thalle grisâtre, peu épais, continu, formant çà et là de petits îlots. Apothécies hémisphériques, souvent plus ou moins difformes et déprimées, 


\section{$2 \mathrm{BHL}$ Biodiversity Heritage Library}

Bouly de Lesdain, Maurice. 1905. "Notes lichénologiques. II." Bulletin de la Société botanique de France 52, 495-498.

https://doi.org/10.1080/00378941.1905.10829186.

View This Item Online: https://www.biodiversitylibrary.org/item/8674

DOI: https://doi.org/10.1080/00378941.1905.10829186

Permalink: https://www.biodiversitylibrary.org/partpdf/19755

\section{Holding Institution}

Missouri Botanical Garden, Peter H. Raven Library

\section{Sponsored by}

Missouri Botanical Garden

\section{Copyright \& Reuse}

Copyright Status: Public domain. The BHL considers that this work is no longer under copyright protection.

This document was created from content at the Biodiversity Heritage Library, the world's largest open access digital library for biodiversity literature and archives. Visit BHL at https://www.biodiversitylibrary.org. 